\title{
ANALYSIS OF THE RELATION BETWEEN CLIMATE CHANGES AND SECURITY AREA
}

\author{
Nikolay Iliyanov PADAREV \\ „Vasil Levski” National Military University, Veliko Tarnovo, Bulgaria \\ nikolai_padarev@abv.bg
}

\begin{abstract}
Security is often used in most meaningful concepts of contemporary political vocabulary. Furthermore, it concerns interesting aspects of the survival of nations and states in the world. In the first decade of the 21st century, mankind got into a qualitatively new phase of its development, in which it should invariably use the "uncertainty" area. There are no doubts about the facts that environmental pollution can cause a variety of ecologically based diseases and this in turn leads to reduction in the average life expectancy. This paper analyzes the relations between climate changes today and their impact on the security area. Problems that have arisen worldwide and in the Republic of Bulgaria because of the climate change are pointed out. The paper discuses directions for improving the security environment in the context of climate changes.
\end{abstract}

\section{Keywords: climate, security}

\section{Introduction}

Security is a condition for stability of the system's equilibrium. Security of the system exists if at any impact that seeks to deviate it from the equilibrium, the system retains its ability to return to it. In the first decade of the 21 st century, humanity moved to a new phase of its development, and in the study of this new phase, the word "uncertainty" is invariably used. [1]

Recently, the origin of threats to the security and the comfort of human's life are increasingly associated with the unfavourable state of the environment.

Undoubtedly, environmental pollution can cause a number of ecologically based diseases which lead to reduction of average life expectancy of people. Hence, the average life expectancy is becoming an important criterion for security, and especially for environmental security. The concept of "Environmental security" can be referred to many areas, such as medicine, industry and technology, agriculture, services, international relations, etc. In other words "Environmental security" has an increasing influence on our lives.

The threat has been defined by several authors in their publications [7-10]. After the analyses of these publications, the following conclusions have been made:

- identifies primarily with the sources of hazardous and harmful factors;

- it is not presented in a logical chain in which the dynamics of the risk factors and their relation to the normative indicators is derived;

- spatial and temporal reconciliation is not considered.

Thomas Smith, in his article [11], makes an analysis, based on past temperature anomalies. NOAA National Centers for Environmental Information published online graphs and maps in which reviewing climate changes in the World [12]. 


\section{Causes of Climate Change}

Climate change is perhaps the most important problem faced by the international community at the moment because other global issues such as biodiversity conservation, clean drinking water, protecting marine resources and forest conservation, poverty, provision of food and conditions for people's well-being will invariably influenced by the changes in the global climate.

The Earth emits to the atmosphere the same amount of radiation and heat as it absorbs from the Sun. The internal redistribution of the radiation that the planet ultimately radiates in the surrounding space largely depends on the composition of the atmosphere or its greenhouse effect, respectively. [2]. In atmosphere there are about 30 greenhouse gases as known, predominantly those of natural origin. About 30 greenhouse gases are known, predominantly those of natural origin. Among them, water vapor $(\mathrm{H} 2 \mathrm{O})$ plays the most important role - they contribute to the greenhouse effect with $66 \%$, carbon dioxide (CO $61 \%$, methane $(\mathrm{CH})$ - to $15 \%$, chlorofluorocarbons (CIFC) - $11 \%$, nitrogen oxides $\left(\mathrm{NO}_{\mathrm{x}}\right)$ - to $4 \%$, ozone $\left(\mathrm{O}_{3}\right)$ and others.[3] The greenhouse effect and the warming of the Earth are closely related to amount of greenhouse gases and their importance for its formation.

According to the Fourth Report of the Intergovernmental Panel on Climate Change (2007), they say that human activity since 1750 has led to an increase in the global temperature. Some scientists who underestimate the role of natural factors are challenging this conclusion. [4] Despite the controversial views of scientists, causes that have led to global climate change nowadays, majority of them believe that greenhouse gases emitted into the atmosphere, primarily by industry, transport and agriculture can cause irreversible climate change.

\section{Global warming effect on Earth's security.}

For the period 1906 - 2005 it was found that the average global ground air temperature of the planet increased by $0.74{ }^{\circ} \mathrm{C}$. In Europe it was more noticeable $-0.8-1.0{ }^{\circ} \mathrm{C}$. It was proved that the last two decades were the warmest on the continent [5]. These seemingly insignificant changes in temperature have already caused global changes in the climate of the planet and, as a result, have changed the living conditions of organisms and ecosystems. The effects of climate change vary considerably across Europe, with a clear impact on the Mediterranean, North-West, Arctic and mountain regions. There is a decrease in snow cover in most areas of the world, especially in spring (on the North Pole between 1950 and 2000, the surface of the ice coat decreased by $20 \%$ ). The sea level rose by about $15 \mathrm{~cm}$ in the 20th century. Increasing average temperatures and decreasing water resources can increase vulnerability to drought, forest fires and heat waves in North-western Europe. Low coastal areas face the challenge of rising sea levels and resulting increased risk of tidal waves in case of storms. [5].

Temperature increases are expected to be higher than the Arctic average temperatures, which will exert considerable pressure on sensitive ecosystems. There is a significant increase in frequency and power of the natural disasters such as hurricanes, earthquakes and floods.

Mountain areas face significant challenges, including a reduction in snow cover, a potential negative impact on winter tourism and the disappearance of many animal species. Reducing soil frost in mountain regions can cause infrastructure problems. Most of the glaciers in the European mountains have already been melting which also has an impact on the water resource management. In the Alps, for example, glaciers have lost about two-thirds of their volume since 1850. An increase in their retreat has also been observed since 
1980. Similarly, coastal and river areas in Europe are particularly vulnerable to climate change as well as cities and urban areas.

Since the end of the 1970's there has been a tendency for warming in Bulgaria. 2009 is one of the 10 warmest years and the decade 2000-2009 was warmer than the previous period (1990-1999), 18 of the last 21 years since 1989 have positive anomalies of the average annual air temperature relative to the baseline weather norm for the period 1961-1990. The average annual temperature in 2009 was $1.2^{\circ} \mathrm{C}$ above the climatic norm.

Under the auspices of the CECILIA project, climate scenarios for Bulgaria were simulated by applying the regional model ALADIN. [6]

In the second half of 20th century, winters were milder and thickness of the snow cover diminished. The average annual temperature in 2009 was $1.2{ }^{\circ} \mathrm{C}$ above the climate norm. In recent years, the frequency of extreme meteorological and climatic phenomena (heavy rainfall, thunderstorms, hailstorms, etc.) has increased. In some regions of the country (Dobrudzha, the southern part of North-western Bulgaria in the area of Kazanluk), weather conditions cause a reduction in the duration of the actual vegetation period up to or less than 90 days. According to the global forecasts, there will be an increase of the average temperature of the Earth by $1^{\circ} \mathrm{C}$ until 2025 and by 2100 - by $3^{\circ} \mathrm{C}$. For Bulgaria, the forecast indicates an increase of $1.2^{\circ} \mathrm{C}$ in the beginning of the $21 \mathrm{st}$ century and 4.0 to $4.5^{\circ}$ $\mathrm{C}$ in 2070 . The forecast is based on a twofold increase in greenhouse gas emissions by 2070 using a simulated model (GFDL) from the United States.

A number of authors classify the risks to the environment in two categories: objective and subjective. Causes of climate changes are also objective (natural) and subjective (technogenic). Since the damage can be of different nature, it is appropriate to determine the average risks of the security environment that are affected by climate change. The impact of the security environment can be presented as follows (1):

$R=\sum_{i}^{n} P_{i} V_{i}$

where, $P=$ The likelihood of serious injury $V_{i}$ as a result as a dangerous moments, $V_{i}=$ the burden of the damage, $n=$ number of damage types.

Continuous dependence of $P_{i}=$ of the magnitude of the damage $V_{i}=$ the average risk.

The exposed dependencies relate to the natural and technogenic causes of climate change risks on the security environment.

\section{Projected impacts of climate change on the security environment.}

- Impact on the water resources. The climate change is likely to worsen quality of water for consumption due to higher temperatures and greater pollution. Europe's water resources and their management are under pressure now, under the current climate. The results of water resources research in Bulgaria based on the modern simulation models, show that the annual river runoff is likely to be reduced in the $21 \mathrm{st}$ century.

- Impact on the human health. The actual occurrence of diseases is highly dependent on local environmental conditions.

- Impact on the forest ecosystems. For most of Europe, it is possible to increase forest productivity, at least in the short term, due to the longer growth period and increased $\mathrm{CO}_{2}$ concentrations in the air. Data from the inventory of European forests show an increase in growth rate. On the other hand, harvesting in the Mediterranean region is likely to decline, and the risks of drought and forest fires will increase. Given that $61 \%$ of forests in Bulgaria are in the area up to $800 \mathrm{~m}$ above sea level, it is clear that the 
majority of Bulgarian forests will be vulnerable.

- Impact on the agro-ecosystems. Climate warming in northern Europe as a whole will have a positive effect on agriculture, while some agricultural production systems in southern Europe are likely to be endangered.

- Impact on settlements, energy and industry. The main direct risk to settlements from climate change is floods, landslides, and rising sea levels. Most vulnerable to climate change are settlements whose main source of income is agriculture, forestry, fishing and others. Some energy products and distribution systems can be significantly affected by climate change, which may lead to reduced consumption or a drop in the security of energy systems.

\section{Conclusions}

Research on the security environment in our times is up to date as we live in a dynamically changing environment in which there are many variables, some of which have a negative potential. In the last decades, mankind has witnessed the changes of the Earth's climate that human influence has made. As a result, the number of natural disasters that end tragically for many people has increased. As a result of the main sources of greenhouse gas emissions, country policies should aim at promoting environmental sustainability and combating climate change. The impact of climate change on the security environment is focused on:

- Increasing the level of the world ocean.

- Long-lasting drought and devastating consequences for agriculture.

- Reduction of crop yields.

- Reducing biodiversity on a regional and global scale due to changed living conditions

\section{References}

[1] Slatinski N., Security: essence, meaning and content, Sofia, Bulgaria, MP, 2011, pp. 410 .

[2] Petkov, G., G. Kostadinova, Air pollution and impacts on the ecosystems, S. Zagora, Bulgaria, Tr. university, pp. 20-202, 2008.

[3] Bajkov, B., Ecology for everyone, NBU, Sofia, Bulgaria, 2000 , pp. 106-119.

[4] Aleksandrov, B., P. Simeonov, Climate change, Sofia, Bulgaria, NMIH-BAN, 2010, pp. 16-32.

[5] http://eo.ucar.edu/learn/1 4 1.htm.

[6] http://www.cecilia-eu.org/.

[7] Kerr W., Complementary theories of safety psychology, Journal of social psychology, 1957, pp.3-29.

[8] Kumamoto H., E. Henley, Probabilistic Assessment and Management for Engeneers and scientists, New York, IEEE Press, 1996, pp 596.

[9] Ferson S, W. Root, R. Kuhn, Risk Calculation-Risk Assessment with Uncertain Numbers, Applied Biomathematics, Setauket, New York, 1999, 278pp.

[10] Mintz A., The inference of accident liability from the accident report. Journal of applied psychology, 1954, pp. 401-406.

[11] https://www.ncdc.noaa.gov/monitoring-references/docs/smith-et-al-2008.pdf

[12] https://www.ncdc.noaa.gov 